\title{
ANALISIS CITRA MEREK, PERIKLANAN, WORD OF MOUTH TERHADAP KEPUTUSAN PEMBELIAN KOSMETIK WARDAH di UNIBA SURAKARTA
}

\author{
Furaida Nur Afifah ${ }^{1}$, Bambang Mursito ${ }^{2}$, Rochmi Widayanti ${ }^{3}$ \\ Program Studi Manajemen Universitas Islam Batik Surakarta \\ Email: ${ }^{1}$ furaida19@gmail.com
}

\begin{abstract}
This research aim to determine the effect of brand image, advertising and word of mouth on Wardah cosmetic purchasing decisions in UNIBA Surakarta. This research uses quantitative research type. Population of this research is UNIBA female students majoring in economics and taken 100 people as samples. Sampling technique using purposive sampling method. Data were obtained by giving questionnaires to student who use or ever use Wardah cosmetic at least once. Data analysis technique using multiple linier regression. The result of data analysis found that brand image, advertising and Word of mouth have effect to purchasing decision simultaneously or partially.
\end{abstract}

Keywords: Brand Image, Advertising, Word Of Mouth, Purchasing Decisions

\section{PENDAHULUAN}

Kehidupan di zaman modern telah menawarkan kemudahan dan kepraktisan dalam menunjang penampilan salah satunya dengan penggunaan produk kecantikan atau kosmetik. Di Indonesia kosmetik telah dijadikan salah satu kebutuhan yang penting bagi sebagian masyarakat terutama kalangan perempuan karena dengan menggunakan produk kosmetik dianggap dapat meningkatkan kepercayaan diri dan menjadikan penampilan terlihat semakin menarik. Saat ini telah banyak beredar berbagai kosmetik yang berasal dari perusahaan lokal dan luar negeri, hal ini menyebabkan terjadinya persaingan yang semakin ketat (Wulandari dan Iskandar, 2018).

Persaingan yang terjadi menuntut perusahaan untuk melakukan dan merencanakan berbagai strategi pemasaran yang dapat mempengaruhi keputusan pembelian konsumen. Keputusan pembelian sendiri merupakan tindakan yang dilakukan setelah konsumen mengetahui kebutuhannya dan mencari informasi serta memilih dari beberapa alternatif yang paling sesuai dengan kebutuhannya. Keputusan pembelian sangat berperan penting, dikarenakan semakin banyak konsumen yang melakukan pembelian produk maka perusahaan tersebut akan mengalami perkembangan dan kemajuan. Keputusan pembelian konsumen dapat dipengaruhi oleh beberapa faktor antara lain : citra merek, periklanan, dan word of mouth (Tampinongkol dan Mandagie, 2018).

Citra merek menjadi salah satu pertimbangan konsumen sebelum melakukan pembelian kosmetik. Dikarenakan citra merek merupakan presepsi konsumen terhadap suatu produk yang tertanam dalam ingatan setelah konsumen melihat, membaca, mendengar, dan merasakan sendiri. Citra merek 
dapat mempengaruhi keputusan pembelian apabila merek telah dikenal luas dan memiliki citra positif di mata konsumen (Dewi, Hartono, dan Istiqomah, 2017).

Citra merek positif tidak terbentuk begitu saja, tetapi perusahaan masih perlu melakukan berbagai upaya yang dapat membentuk citra merek positif. Salah satunya perusahaan dapat melakukan promosi melalui periklanan. periklanan merupakan promosi berbayar yang dilakukan perusahaan melalui media cetak, media elektronik, media penyiaran, media jaringan, dan media display. Pradiani dan Ningtyas (2017) berpendapat bahwa periklanan memiliki pengaruh signifikan terhadap keputusan pembelian. Namun menurut Edbert, Tumbel, dan Tumbuan (2014) periklanan memiliki pengaruh tetapi tidak signifikan terhadap keputusan pembelian.

Selain citra merek dan periklanan faktor word of mouth juga dapat mempengaruhi keputusan pembelian konsumen. Word of mouth merupakan pemasaran dari mulut kemulut yang dilakukan konsumen yang telah menggunakan produk. Word of mouth merupakan pemasaran yang tidak memerlukan biaya yang besar karena dilakukan oleh konsumen yang merasa puas dan dengan sendirinya menceritakan mengenai kelebihan-kelebihan yang dimiliki suatu produk serta merekomendasikannya kepada orang lain. Word of mouth dapat mempengaruhi keputusan pembelian dikarenakan beberapa calon konsumen akan lebih mempercayai cerita pengalaman dan rekomendasi orang lain, apabila informasi yang didapat positif maka konsumen akan tertarik melakukan pembelian (Mahendrayasa, Kumadji, dan Abdillah, 2014).

Wardah merupakan salah satu brand kosmetik lokal yang didirikan PT. Pusaka Tradisi Ibu yang pada tahun 2011 berganti nama menjadi PT. Paragon Technology and Innovation (PTI). Perusahaan ini didirikan pada tanggal 28 February 1985 oleh pasangan suami istri Drs. H. Subakat Hadi, M. Sc dan Dra. Hj. Nurhayati Subakat, Apt. Pada awal berdiri PTI hanya memproduksi produk perawatan rambut yang kemudian pada tahun 1995 mulai mengembangkan merk kosmetik Wardah yang mengusung label halal dan aman karena telah memiliki sertifikat halal dari LPPOM MUI dan menggunakan bahan baku yang telah memiliki nomer registrasi dari Departemen Kesehatan.

Wardah berhasil mendapatkan Halal Reward 2011 untuk kategori Brand Kosmetik halal dan penghargaan The $2^{\text {nd }}$ Indonesia Original Brand 2011 versi majalah SWA, Wardah juga mengikuti Halal \& Healthy Product Fair di CNR Expo, Turki dan membuka Store pertamanya di fX Sudirman. Kemudian pada tahun 2012 Wardah kembali meraih penghargaan The $1^{\text {st }}$ Indonesia Original Brand 2012 versi majalah SWA dan membuka Outlet sekaligus Store pertama di Malaysia. Pada tahun 2013 Wardah telah membuka 22.000 Outlet di Indonesia dan Malaysia.

Berdasarkan latar belakang diatas, maka penulis berpendapat layak melakukan penelitian dengan judul "Analisis Citra Merek, Periklanan, Dan Word Of Mouth Terhadap Keputusan Pembelian Kosmetik Wardah."

\section{METODOLOGI PENELITIAN}

Penelitian ini menggunakan jenis penelitian kuantitatif. Tempat penelitian dilakukan di Universitas Islam Batik Surakarta. Populasi penelitian ini adalah seluruh mahasiswa perempuan Universitas Islam Batik Surakarta Jurusan Ekonomi yang berjumlah 972 orang. Dalam menentukan jumlah sampel menggunakan teori yang dikemukakan arikunto (2012: 73), jika 
populasi 100 diambil semua populasinya, tetapi jika populasi lebih dari 100 maka diambil 10$15 \%$ atau $20-25 \%$ dari jumlah populasi. Sampel penelitian ini mengambil $10 \%$ dari populasi sehingga diperoleh 972 × 10\% =97,2 dibulatkan menjadi 100 responden yang dijadikan sebagai sampel. Teknik pengambilan sampel menggunakan purposive sampling. Pengumpulan data dilakukan dengan memberikan kuesioner kepada mahasiswa UNIBA jurusan ekonomi yang menggunakan atau pernah menggunakan produk kosmetik Wardah. Untuk menganalisis data penelitian ini menggunakan analisis regresi linier berganda.

\section{HASIL DAN PEMBAHASAN}

\section{Hasil uji normalitas}

Uji normalitas digunakan untuk menguji apakah variabel independen (citra merek, periklanan, dan word of mouth) dan dependen (keputusan pembelian) memiliki data yang berdistribusi normal. Data berkontribusi normal jika Asymp.sig lebih besar dari 0,05. Untuk menguji normalitas dapat menggunakan kolmogrov-Smirnov dengan bantuan SPSS Statistic versi 21.

Hasil uji normalitas dapat dilihat pada tabel 1.

Tabel 1

Hasil Uji Normalitas

\begin{tabular}{|c|c|c|}
\hline Model & Unstandardized Residual & Keterangan \\
\hline $\mathrm{N}$ & 100 & \\
\hline Kolmogrov- & 1,161 & \\
\hline $\begin{array}{l}\text { Smirnov } \mathrm{Z} \\
\text { Asvmn Sig (2 tailed) }\end{array}$ & Data berdistribusi & normal ,135 \\
\hline
\end{tabular}

Hasil pengujian menunjukan Asymp. Sig (2 tailed) 0,135 > 0,05, artinya data sebaran berdistribusi normal.

\section{Hasil uji multikolinearitas}

Pengujian multikolinearitas digunakan untuk mengetahui ada tidaknya hubungan antara masing-masing variabel independen (citra merek, periklanan, dan word of mouth). Hasil uji multikolinearitas dapat dilihat pada tabel 2 .

Tabel 2

Hasil Uji Multikolinearitas

\begin{tabular}{|c|c|c|}
\hline Model & Nilai Tolerance Value & VIF \\
\hline Citra Merek & ,734 & 1,362 \\
\hline Periklanan & ,818 & 1,222 \\
\hline Word Of Mouth & ,639 & 1,564 \\
\hline
\end{tabular}

Berdasarkan tabel 2 menunjukan nilai VIF dari variabel citra merek (1,362), periklanan $(1,222)$, dan word of mouth memiliki nilai VIF lebih kecil 10, maka tidak terdapat adanya multikolinearitas. 


\section{Hasil uji heteroskidasitas}

Uji heteroskidasitas digunakan untuk mengetahui ketidaksamaan varians dari pengamatan satu dengan pengamatan lain. Hasil yang uji heteroskidasitas dapat dilihat pada tabel 3 .

Tabel 3

Hasil Uji Heteroskedasitas

\begin{tabular}{ccc}
\hline Model & Sig & Keterangan \\
\hline (Constant) &, 706 & Tidak Terjadi Heterokedasitas \\
Citra Merek &, 965 & Tidak Terjadi Heterokedasitas \\
Periklanan &, 348 & Tidak Terjadi Heterokedasitas \\
Word Of Mouth &, 140 & Tidak Terjadi Heterokedasitas \\
\hline
\end{tabular}

Bardasarkan tabel 3 yang didapat dengan melakukan pengujian menggunakan SPSS versi 21 menunjukan hasil nilai signifikan dari variabel citra merek $(0,965)$, periklanan $(0,348)$, dan word of mouth $(0,140)$ memiliki nilai signifikan yang lebih besar dari 0,05 , maka tidak terdapat adanya heteroskedasitas.

\section{Hasil Analisis Data}

\section{Regresi Linier Berganda}

Digunakan untuk mengetahui seberapa besar variabel citra merek, periklanan, dan word of mouth mempengaruhi keputusan pembelian. Hasil uji regresi linier berganda dapat dilihat pada tabel 4 .

Tabel 4

Hasil Regresi Linier Berganda

\begin{tabular}{ccc}
\hline \multirow{2}{*}{ Model } & Unstandardized Coefficients & \multirow{2}{*}{ Std. Error } \\
\hline B Constant) & 3,787 & 1,769 \\
Citra Merek &, 247 &, 082 \\
Periklanan &, 270 &, 069 \\
Word Of Mouth &, 286 &, 079 \\
\hline
\end{tabular}

Berdasarkan tabel 4 diperoleh hasil a $(3,787), b_{1}(0,247), b_{2}(0,270)$, dan $b_{3}(0,286)$, maka persamaan regesi linier berganda memiliki rumus sebagai berikut $\mathrm{Y}=$ $3,787+0,247 \mathrm{X}_{1}+0,270 \mathrm{X}_{2}+0,286 \mathrm{X}_{3}+\mathrm{e}$.

\section{Uji F}

Uji F digunakan untuk mengetahu apakah variable independen memiliki pengaruh terhadap variabel dependen secara simultan. Hasil dari uji F dapat dilihat pada tabel 5. 
Tabel 5

Hasil Uji F

\begin{tabular}{cccc}
\hline Model & F & Sig & Keterangan \\
\hline Regression Residual Total & 30,823 & 0,000 & $\mathrm{H}_{\mathrm{a}}$ ditolak \\
\hline
\end{tabular}

Berdasarkan tabel 5 diperoleh hasil $\mathrm{F}_{\text {hitung }}>\mathrm{F}_{\text {tabel }}(30,823>2,70)$ dengan nilai signifikan $0,000<0,05$, maka $\mathrm{H}_{\mathrm{o}}$ ditolak, variabel citra merek, periklanan dan word of mouth secara simultan memiliki pengaruh terhadap keputusan pembelian kosmetik Wardah pada mahasiswa Universitas Islam Batik Surakarta.

\section{Uji t}

Uji t digunakan untuk mengetahui apakah variabel independen memiliki pengaruh terhadap variabel dependen secara parsial. Hasil perhitungan uji t dapat dilihat pada tabel 6 .

Tabel 6

Hasil Uji t

\begin{tabular}{ccccc}
\hline Model & B & T & Sig & Keterangan \\
\hline (Constant) & 3,787 & 2,141 &, 035 & \\
Citra Merek &, 247 & 3,025 &, 003 & $\mathrm{H}_{1}$ Diterima \\
Periklanan &, 270 & 3,933 &, 000 & $\mathrm{H}_{2}$ Diterima \\
Word Of Mouth &, 286 & 3,616 &, 000 & $\mathrm{H}_{3}$ Diterima \\
\hline
\end{tabular}

Pada variabel citra merek hasil $t_{\text {hitung }}(3,025)>t_{\text {tabel }}(1,988)$ dengan nilai signifikan 0,003 $<0,05$ yang artinya $\mathrm{H}_{\mathrm{a}}$ diterima, maka citra merek memiliki pengaruh signifikan terhadap keputusan pembelian kosmetik Wardah pada mahasiswa Universitas Islam Batik Surakarta.

Pada variabel periklanan hasil $t_{\text {hitung }}(3,933)>t_{\text {tabel }}(1,988)$ dengan nilai signifikan 0,000 $<$ 0,05 yang artinya $\mathrm{H}_{\mathrm{a}}$ diterima, periklanan memiliki pengaruh signifikan terhadap keputusan pembelian kosmetik Wardah pada mahasiswa Universitas Islam Batik Surakarta.

Pada variabel word of mouth hasil $t_{\text {hitung }}(3,616)>t_{\text {tabel }}(1,988)$ dengan nilai signifikan $0,000<0,05$ yang artinya $H_{a}$ diterima, word of mouth memiliki pengaruh signifikan terhadap keputusan pembelian kosmetik Wardah pada mahasiswa Universitas Islam Batik Surakarta.

\section{Koefisien determinasi}

Koefisien determinasi digunakan untuk mengatahui besar kontribusi variabel citra merek, periklanan, dan word of mouth terhadap keputusan pembelian. Hasil penghitungan koefisien determinasi dapat dilihat pada tabel 7.

Tabel 7

Hasil Koefisien Determinasi

\begin{tabular}{ccc}
\hline $\mathbf{R}$ & R Square & Adjusted R Square \\
\hline, $700^{\mathrm{a}}$ & 0,491 & 0,475 \\
\hline
\end{tabular}

Nilai Adjusted $\mathrm{R}^{2}$ sebesar 0,475 yang artinya 47.5\% keputusan pembelian kosmetik Wardah pada mahasiswa Universitas Islam Batik Surakarta dipengaruhi oleh citra merek, 
periklanan, dan word of mouth. Sedangkan sisanya yang sejumlah 52,5\% dipengaruhi variabel lain diluar variabel penelitian, seperti harga, kualitas pelayanan, kualitas produk, dan lokasi.

\section{Pembahasan}

Citra merek menjadi salah satu faktor yang dapat mempengaruhi keputusan pembelian kosmetik Wardah pada mahasiswa Universitas Islam Batik surakarta dikarenakan konsumen menganggap Wardah memiliki citra merek yang baik. Berdasarkan hasil uji t diperoleh hasil bahwa citra merek memiliki pengaruh signifikan terhadap keputusan pembelian kosmetik Wardah pada mahasiswa Universitas Islam Batik Surakarta. Hal ini didasari pada hasil $t_{\text {hitung }}$ lebih besar dari $t_{\text {tabel }}(3,025>1,988)$ dengan nilai signifikan $0,003<0.05$. Artinya apabila semakin baik citra merek yang dimiliki oleh kosmetik Wardah, maka akan meningkatkan keputusan pembelian. Hasil penelitian ini sejalan dengan penelitian yang dilakukan oleh Oladepo dan Abimbola (2015); Sari (2013).

Periklanan dapat mempengaruhi keputusan pembelian kosmetik Wardah pada mahasiswa Universitas Islam Batik Surakarta karena konsumen menganggap iklan wardah menarik. Berdasarkan hasil uji $t$ diperoleh hasil bahwa periklanan memiliki pengaruh signifikan terhadap keputusan pembelian kosmetik Wardah pada mahasiswa Universitas Islam Batik Surakarta. Hal ini didasari pada hasil $t_{\text {hitung }}$ lebih besar dari $\mathrm{t}_{\text {tabel }}(3,933>1,988)$ dengan nilai signifikan $0,000<0.05$. Artinya apabila periklanan yang dilakukan kosmetik Wardah baik dan menarik, maka dapat meningkatkan keputusan konsumen. Hasil penelitian ini sejalan dengan penelitian yang dilakukan oleh Bakara (2013).

Word of mouth dapat mempengaruhi keputusan pembelian kosmetik Wardah pada mahasiswa Universitas Islam Batik Surakarta karena banyak konsumen yang tertarik membeli setelah mendapat rekomendasi dan melihat review orang lain. Berdasarkan hasil uji t diperoleh hasil bahwa word of mouth memiliki pengaruh signifikan terhadap keputusan pembelian kosmetik Wardah pada mahasiswa Universitas Islam Batik Surakarta. Hal ini didasari pada hasil $t_{\text {hitung }}$ lebih besar dari $t_{\text {tabel }}(3,616>1,988)$ dengan nilai signifikan $0,000<0,05$. Artinya apabila semakin sering terjadi word of mouth positif, maka keputusan pembelian dapat mengalami peningkatan. Hasil penelitian ini sejalan dengan penelitian yang dilakukan oleh Basri, Ahmad, Anuar, dan Ismail (2016); Arda (2017).

Berdasarkan hasil uji F menunjukan bahwa citra merek, periklanan, dan word of mouth secara simultan memiliki pengaruh terhadap keputusan pembelian kosmetik Wardah pada mahasiswa Universitas Islam Batik Surakarta.

Hal ini didasari pada hasil $\mathrm{F}_{\text {hitung }}$ lebih besar dari $\mathrm{F}_{\text {tabel }}(30,823>2,70)$ dengan nilai signifikan $0,000<0,05$. Hal ini membuktikan semakin besar citra merek, periklanan, dan word of mouth pada keputusan pembelian kosmetik Wardah, maka keputusan pembelian juga akan mengalami peningkatan.

\section{KESIMPULAN}

1) Citra merek, periklanan, dan word of mouth secara simultan memiliki pengaruh terhadap keputusan pembelian kosmetik Wardah pada mahasiswa Universitas Islam Batik Surakarta.

2) Citra merek memiliki pengaruh signifikan terhadap keputusan pembelian kosmetik Wardah pada mahasiswa Universitas Islam Batik Surakarta. 
3) Periklanan memiliki pengaruh signifikan terhadap keputusan pembelian kosmetik Wardah pada mahasiswa Universitas Islam Batik Surakarta.

4) Word of mouth memiliki pengaruh signifikan terhadap keputusan pembelian kosmetik Wardah pada mahasiswa Universitas Islam Batik Surakarta.

\section{Saran}

1. Perusahaan sebaiknya lebih meningkatkan citra merek agar dapat meningkatkan keputusanKpembelian kosmetik Wardah.

2. Perusahaan sebaiknya lebih meningkatkan kualitas periklanan agar konsumen dapat tertarik untuk membeli kosmetik Wardah setelah melihat iklan.

3. Perusahaan sebaiknya lebih meningkatkan kualitas perusahaan dan produknya agar lebih banyak konsumen yang merasa puas sehingga word of mouth positif dapat terjadi.

\section{REFERENSI}

Arda, M. (2017). Analysis Of Effect Of Promotion And Word Of Mouth On Purchase Decision: Case Of Student University Of Muhammadiyah Sumatera Utara. Proceedings of AICS-Social Sciences, 7, 334-341.

Bakara, F. O. (2013). The Influence Of Television Advertising On Purchase Decision Of Teenagers. Jurnal EMBA: Jurnal Riset Ekonomi, Manajemen, Bisnis dan Akuntansi, 1(4).

Basri, N. A. M. H., Ahmad, R., Anuar, F. I., \& Ismail, K. A. (2016). Effect Of Word Of Mouth Communication On Consumer Purchase Decision: Malay 
Upscale Restaurant. Procedia-Social and Behavioral Sciences, 222, 324331.

Dewi, D. R. Hartono, S., \& Istiqomah. (2017). Pengaruh Iklan, Kualitas Produk, Dan Citra Merek Terhadap Keputusan Pembelian Minuman Probiotik Merek Yakult (Studi Kasus Pada Konsumen Yakult Di Kampung Botokan Pajang Laweyan Surakarta). JSSH (Jurnal Sains Sosial dan Humaniora), 1(1).

Edbert, S., Tumbel, A., \& Tumbuan, W. A. (2014). Pengaruh Image, Harga, Iklan, Dan Kualitas Produk Terhadap Keputusan Pembelian Konsumen Pada Pasta Gigi Pepsodent Di Kota Manado. Jurnal EMBA: Jurnal Riset Ekonomi, Manajemen, Bisnis dan Akuntansi, 2(3).

Kotler, P., \& Keller, K. L. 2009. Manajemen Pemasaran. Edisi 13. Jilid 2, Terjemaan Oleh Bab Sabran, MM. Jakarta: Erlangga.

Mahendrayasa, A. C., Kumadji, S., \& Abdillah, Y. (2014). Pengaruh Word Of Mouth Terhadap Minat Beli Serta Dampaknya Pada Keputusan Pembelian (Survei Pada Mahasiswa Pengguna Kartu Selular GSM "IM3" Angkatan 2011/2012 Dan 2012/2013 Fakultas Ilmu Administrasi Universitas Brawijaya Malang). Jurnal Administrasi Bisnis, 12(1).

Oladepo, O. I., \& Abimbola, O. S. (2015). The Influence Of Brand Image And Promotional Mix On Consumer Buying Decision-a Study Of Beverage Consumers In Lagos State, Nigeria. British journal of marketing studies, 3(4), 97-109.

Pradiani, T., \& Ningtyas, D. C. W. (2017). Pengaruh Citra Merek Dan Iklan Terhadap Keputusan Pembelian Produk. Jurnal Akademika, 15(2), 73-78.

Sari, K., \& Kurnia, A. (2013). Pengaruh Citra Merek Dan Keluarga Terhadap Keputusan Pembelian Honda Beat. Jurnal IImu Manajemen (JIM), 1(1).

Tampinongkol, V. M., \& Mandagie, Y. (2018). Analisis Pengaruh Word Of Mouth, Kualitas Produk Dan Brand Image Terhadap Keputusan Pembelian Sepatu Converse Di Manado Town Square. Jurnal EMBA: Jurnal Riset Ekonomi, Manajemen, Bisnis dan Akuntansi, 6(4).

Wulandari, R. D., \& Iskandar, D. A. (2018). Pengaruh Citra Merek Dan Kualitas Produk Terhadap Keputusan Pembelian Pada Produk Kosmetik. Jurnal Riset Manajemen dan Bisnis (JRMB) Fakultas Ekonomi UNIAT, 3(1), 1118. 